\title{
The Use of Horizontal and Vertical Angles in Terrestrial Navigation
}

\section{Zvonimir Lušić}

The methods of determining a ship's position in terrestrial navigation by using vertical and horizontal angles are nowadays rarely used. The reason is the relative complexity of the procedure and the lack of accuracy of some methods. Different methods of using horizontal and vertical angles to obtain the line of position (LOP) will be presented in this paper, as well as the occurring errors and recommendations for use. In this paper, the sextant will be considered a basic instrument for measuring horizontal and vertical angles. The sextant allows a very precise measuring of angles from which very accurate lines of position can be obtained.

\section{KEY WORDS}

$\sim$ Horizontal angles

$\sim$ Vertical angles

$\sim$ Terrestrial navigation

$\sim$ Sextant

\section{INTRODUCTION}

A horizontal angle can be obtained as a difference between two bearings or two relative bearings. The bearing ${ }^{(1)}$ and relative bearing $^{(2)}$ of a ship are usually measured using a pelorus(3) or radar. A better solution for obtaining a horizontal angle is the use of a sextant (Figure 1). The sextant is a primary instrument for celestial navigation, i.e. instrument designed to measure the altitudes of celestial bodies above the visible sea horizon. However, the sextant also allows us to measure the vertical angle of terrestrial objects (the angle between the top of the object and the visible sea or shore horizon) as well as horizontal angle between two points.

Generally speaking, the marine sextant measures the angle between two points by bringing the direct image from one point and a double-reflected image from the other into coincidence, and can usually measure angles up to approximately $120^{\circ}$ (Bowditch, 2002).

The main advantage of the sextant compared to other angle measuring instruments is its precision. For example, the pelorus can measure up to a maximum of $1 / 10$ of a degree (in practice the bearing is usually rounded to a whole degree), while the marine sextant normally measures $1 / 10$ of a minute (Figure 2).

Figure 3 shows a gyro compass repeater and Figure 2 a sextant with micrometer drum and varnier, that reads a fraction of a minute.

1 The true bearing of an object is the clockwise angle in degrees from the north line $\left(000^{\circ}\right)$ to a straight line drawn from the ship to the object.

2 The relative bearing of an object is the clockwise angle in degrees from the heading of the vessel to a straight line drawn from the ship to the object. Heading is the direction in which a ship is pointed at any given moment.

3 Pelorus-compass or compass repeater, with sighting vanes or a sighting telescope attached. 


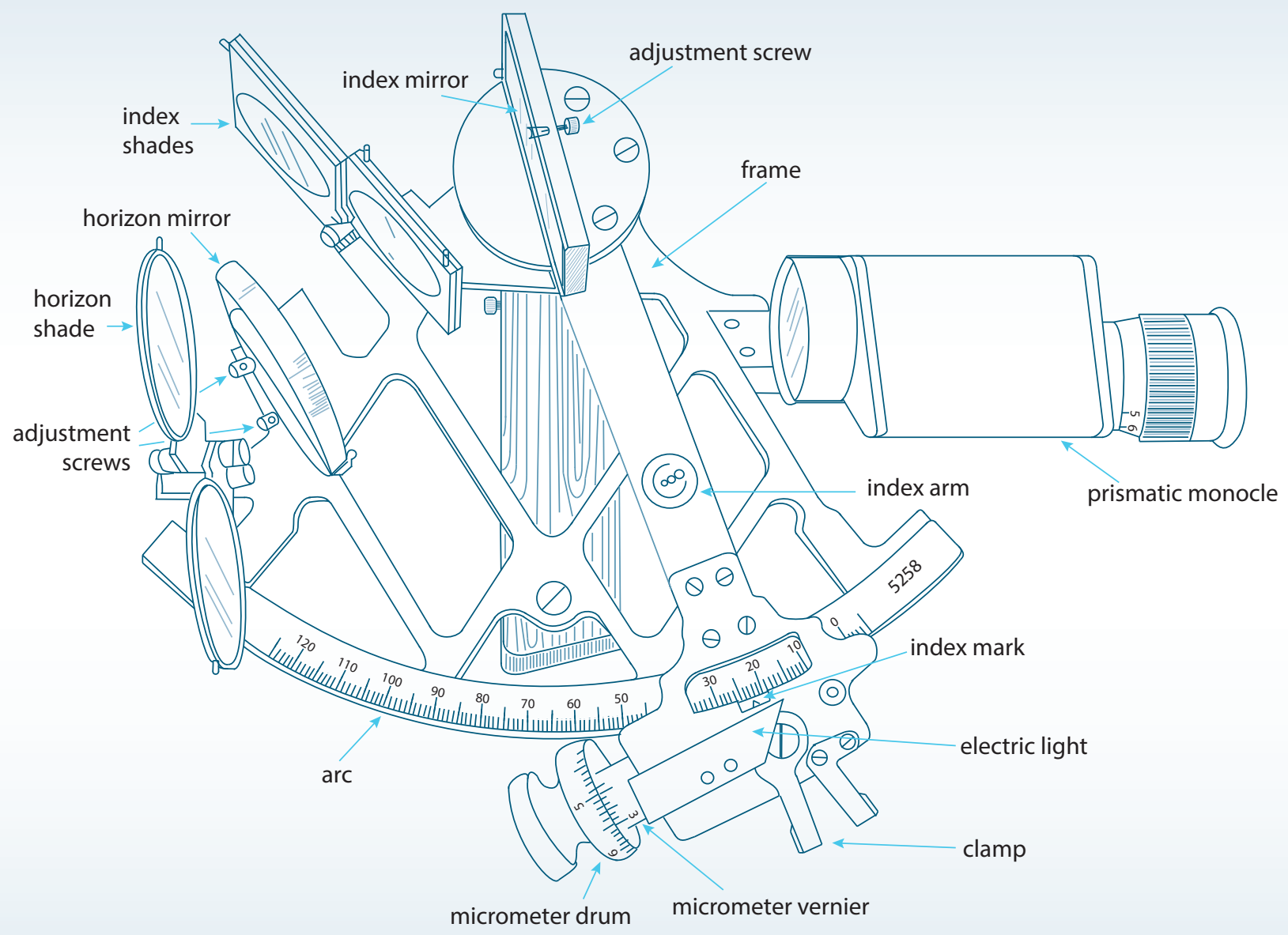

Figure 1. Sextant. Source: Coolen, 1987, p. 494.

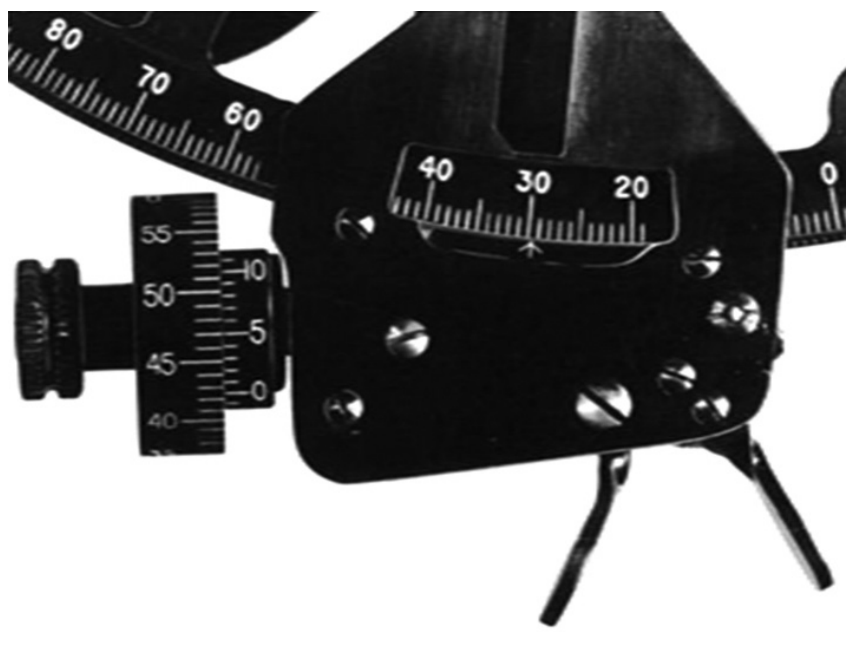

Figure 2. Micrometer drum sextant set at $29^{\circ} 42.5^{\prime}$. Source: Bowditch, 2002, p. 265.

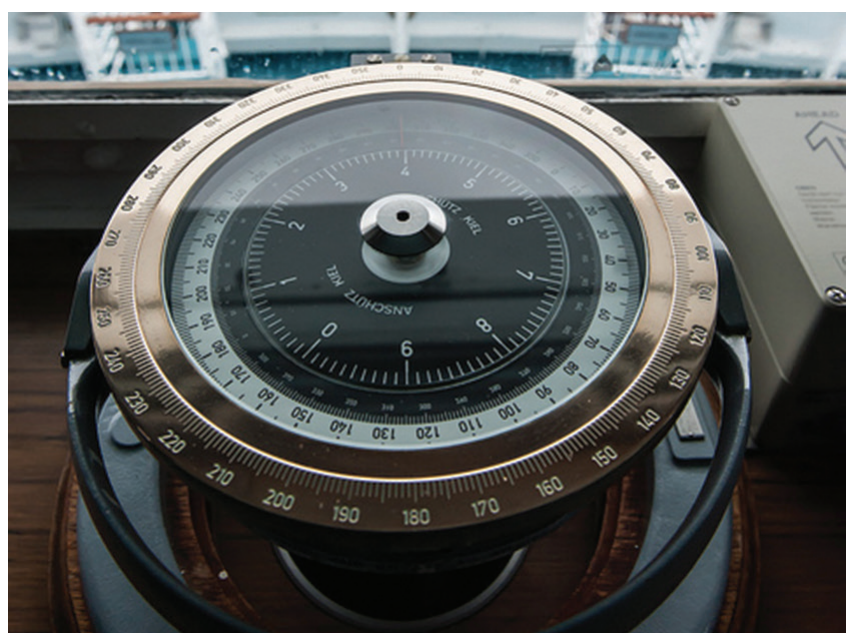

Figure 3. Gyro compass repeater

Source: http://www.flickr.com 

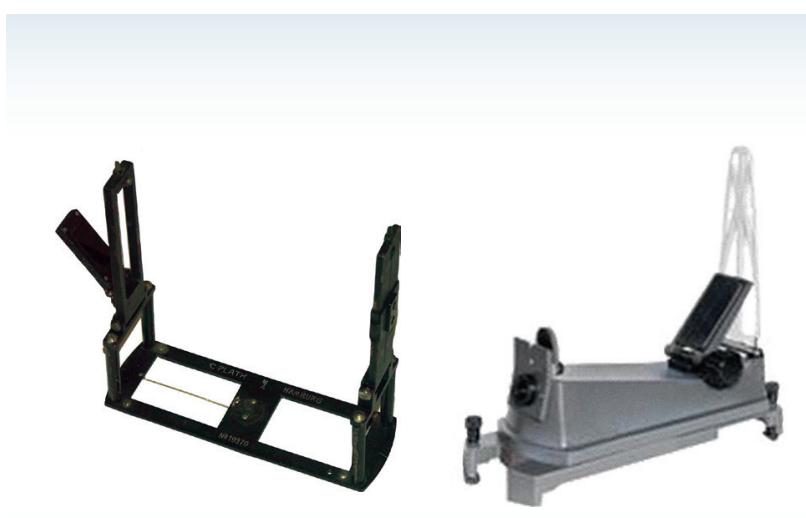

Figure 4. Bearing sight (diopter)

Source: http://www.compassmuseum.com

The mounting of a bearing sight (Figure 4) on top of a compass makes it possible to measure bearings.

Therefore, although the sextant makes the obtainment of very precise vertical and horizontal angles possible, the final accuracy of the associated line of positions will be different. Generally, since the line of position obtained by vertical angles is more complex than the one obtained by horizontal angles, the probability of error is bigger. The main reasons are: the influence of the dip of the sea (or shore) horizon, error in the height of the observer's eye and error in the height of the observed object. These errors have to be taken into consideration during the measurement of the vertical angle. The obtainment of a line of position from a horizontal angle only requires the existence of a horizontal angle between the two charted objects. Knowing the corresponding graphical or numerical methods, it is relatively easy to construct a circle as a line of position on a navigation map (Figure 5 and 6).

In case the vertical angle of a terrestrial object is known, the vertical angle alone is not enough. The height of the observer's eye and the height of the object observed both need to be known. In addition, there is yet another problem with vertical angles of terrestrial objects of known height. The base of the object (shore horizon ${ }^{(4)}$ ) can either be visible (shore horizon within the observer's visible sea horizon) or not (shore horizon beyond sea horizon). Consequently, the resolution of this problem requires the application of different methods. There are also methods for obtaining the line of position by using a vertical angle if the height of the objects is unknown. These methods will also be explained in further text.

Shore horizon-line that separates sea from land.

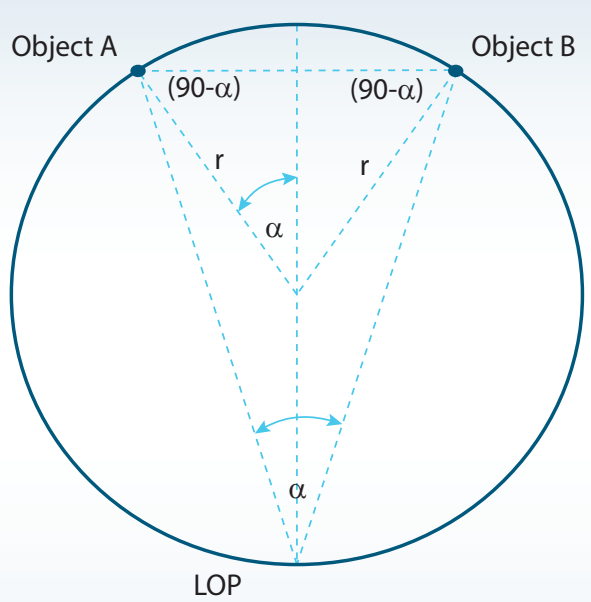

Figure 5. LOP from a horizontal angle ( $\alpha$ ) determination of the radius $(r)$.

\section{LINE OF POSITION FROM A HORIZONTAL ANGLE}

The line of position from a horizontal angle is a circle. To draw a circle, its radius must be known. In this case the radius ( $r$ ) can be determined either mathematically (Figure 5) or graphically (Figure 6).

$r=\frac{A B}{2 \cdot \sin \alpha}$

Figure 6 shows how to graphically obtain LOP from a horizontal angle $\left(\alpha<90^{\circ}\right)$. If a horizontal angle is greater than $90^{\circ}$ the observer lies on the minor arc of a position circle. It means that the auxiliary lines should be plotted under the angle ( $\alpha<90^{\circ}$ ) on

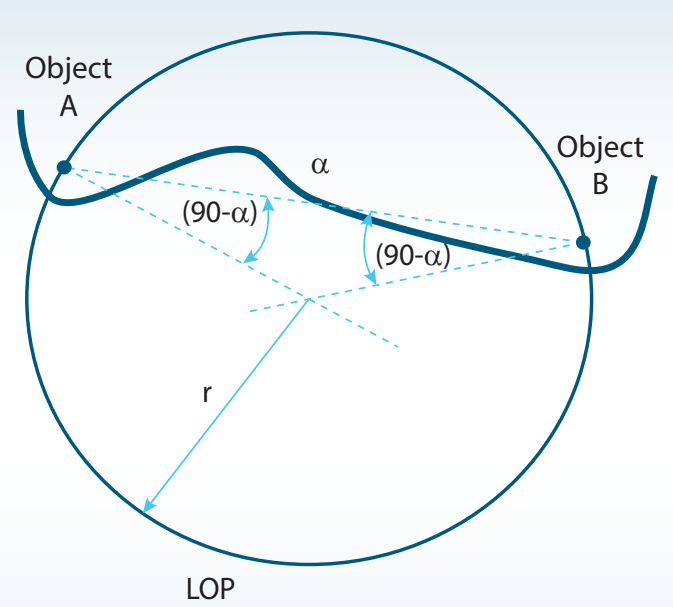

Figure 6. LOP from a horizontal angle ( $\alpha$ ) - graphical construction of LOP. 


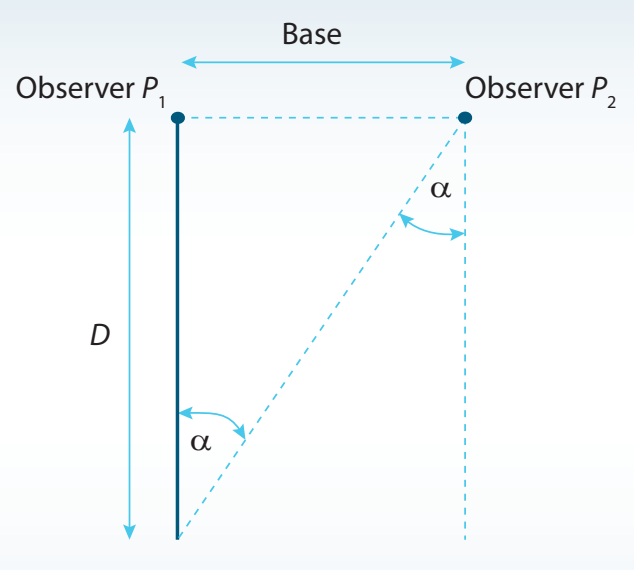

Object A

Figure 7. Distance from a horizontal angle $(\alpha)$.

the opposite side of the base $A B$ in Figure 6.

In some circumstances, the distance from the object observed can also be obtained from the horizontal angle (Figures 7 and 8) (Kos et al., 2010).

Distance $D$ can be calculated from the known length of the base $(B)$ and the parallax angle $\alpha$ (triangle $A, P_{1}, P_{2}$ - Figure 7):

$D=\frac{B}{\tan \alpha}$

This principle uses optical rangefinders.

A similar approach is described in Figure 8. Distance $D$ can be calculated from the known length of the base (between two positions or two observers; points $A$ and $B$ ) and the corresponding horizontal angles $(\alpha, \beta)$ :

$\gamma=180^{\circ}-\alpha-\beta$

$D: D^{\prime}=\sin \beta: \sin \gamma$

$D=\frac{D^{\prime} \cdot \sin \beta}{\sin \gamma}$

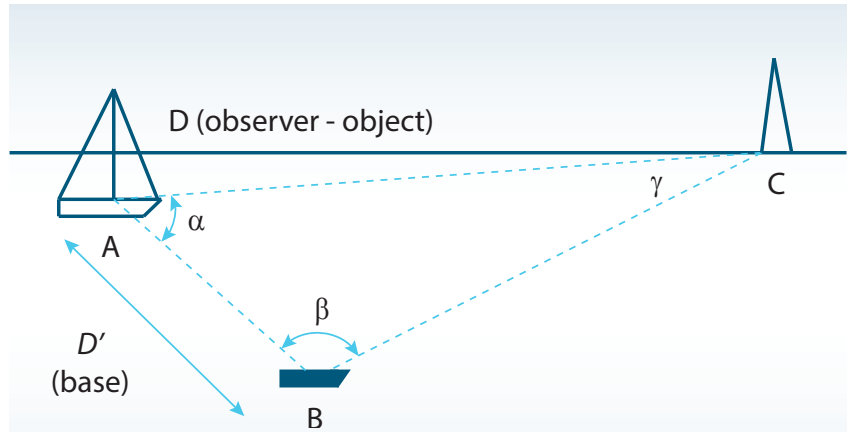

Figure 8. Distance from a two horizontal angles.
Another approach to determining the distance from an object of known length involves the comparison of two triangles; the first enclosed by endpoints of a distant object and a reference point placed between the base and the object, and the second enclosed by endpoints of the base and the reference point (Figure 9). If the length of the base $(L)$ and the distance $\left(d_{1}\right)$ from the base to the reference point (or distance of angle $a$ at the reference point from the base) are known, the distance from the reference point to the object $\left(d_{2}\right)$ can be obtained.

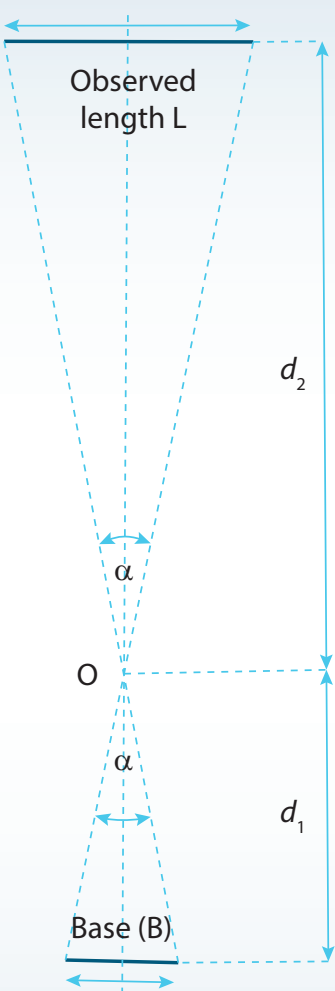

Figure 9. Distance from a horizontal angle knowing the length of base (B) and length of object (L).

$B$ - distance between two observer positions,

$L \quad$ - length of the object,

$d_{1}$ - distance from the base to the reference point,

$d_{2}$ - distance from the reference point to the object.

$d_{2}=\frac{L \cdot d_{1}}{B}$

$D$ (total distance $)=d_{1}+d_{2}$ 


\section{LINE OF POSITION FROM A VERTICAL ANGLE}

The vertical angle can be measured on a terrestrial object of known or unknown height. Likewise, the shore horizon of the observed object can either be visible or beyond the sea horizon.

\subsection{Distance by vertical angle of the object if the height of the object is known}

a) Visible shore horizon

If the height of the object is known and shore horizon visible, the problem of determination of distance from a vertical angle can be solved by a simple right triangle (Figure 10). In this simple case, the impact of the dip of the shore horizon and the height of the observer's eye will not be taken into account.

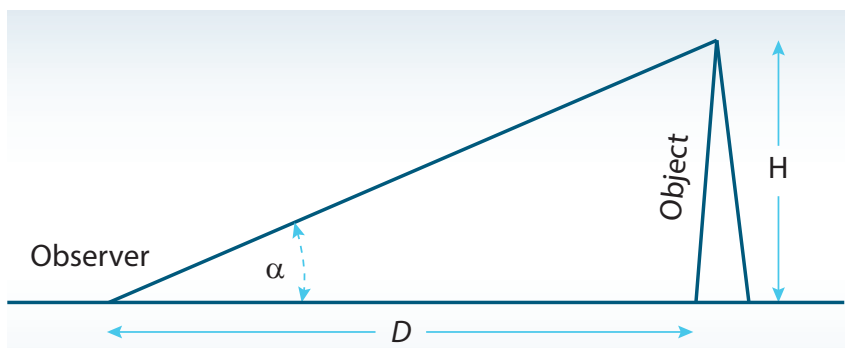

Figure 10. Distance from a vertical angle.

$\alpha$ - vertical angle,

$H$ - height of the object,

$D$ - distance to the object.

$D=\frac{H}{\tan \alpha}$

or (Simović, 2001):

$D=\frac{H}{\alpha \cdot \tan 1^{\prime}}=\frac{H}{\alpha} \frac{3438}{1852}=\frac{13}{7} \frac{H}{\alpha}=1.86 \frac{H}{\alpha}$

Equations (5) or (6) provide the solution based upon the following assumptions:

- the eye of the observer is at sea level,

- the sea surface is flat,

- $\quad$ atmospheric refraction and the dip of a shore horizon are negligible, and

the waterline by the object is vertically bellow the observed peak of the object.

Also, some additional facts about this method (Bowditch, 2002):

- $\quad$ the error due to the height of the eye does not exceed $3 \%$ of the distance $(D)$ for sextant angles under $20^{\circ}$ and the height of the eye less than $1 / 3$ of the object's height,
- $\quad$ the error due to waterline not being below the peak of the object does not exceed $3 \%$ of the distance $(D)$ when the height of the eye is less than 1/3 of the object's height and the offset of the waterline from the base of the object is less than $1 / 10$ of the distance $(D)$,

the errors due to the curvature of the Earth and atmospheric refraction are generally considered negligible for practical use.

A more accurate line of position by vertical angle requires that the height of the observer and the dip of the shore horizon (Figure 11) be taken into consideration.

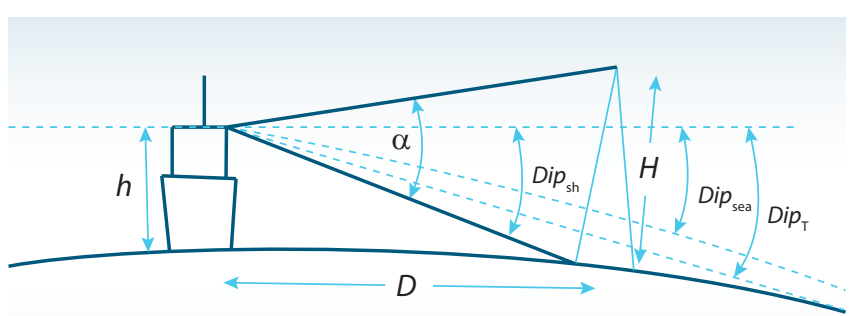

Figure 11. Distance from a vertical angle-visible shore horizon.

$D$ - distance to the object,

$\alpha$ - vertical angle,

$H \quad$ - height of the object above sea level,

Dip $_{\text {sh }}$ - Dip of the shore horizon,

Dip $_{\text {sea }}$ - Dip of the sea horizon,

$\operatorname{Dip}_{\mathrm{T}}$ - True dip.

The distance to the object can be calculated by the following equation (Benković et al., 1986):

$D=1.86 \frac{H-h}{\alpha^{\prime}+D^{i p h}}$

In equation (7), $h$ and $H$ can be expressed in meters (or feet), vertical angle $\alpha$ (corrected for index error of the sextant) in minutes and Dip of the shore horizon (always negative) in minutes.

Most of nautical tables contain tabulated values of the Dip of the shore horizon ${ }^{(5)}$. The Dip of the shore horizon can also be calculated by equation (Coolen, 1995):

$\operatorname{Dip}_{\text {sh }}=\frac{\left(\text { Dip }_{\text {sea }}-D^{\prime}\right)^{2}}{2 D^{\prime}}\left[{ }^{\prime}\right]$

where $D^{\prime}$ is the distance from the observer to the waterline at the

5 For example: (Norie's, 1991), (Nautičke tablice HHI, 1999), (Bowditch, 2002), etc. These same tables offering the calculated distances from the vertical angles. 
object and Dip sea is (Benković et al., 1986):

$$
\text { Dip }_{\text {sea }}=1.77 \sqrt{h}\left[{ }^{\prime}\right]
$$

The True Dip (Benković et al., 1986):

$\operatorname{Dip}_{T}=1.93 \sqrt{h}\left[{ }^{\prime}\right]$

and the Distance of sea horizon:

$$
\text { Dsea }=2.08 \sqrt{h}[\text { n.m. }]
$$

Equation (7) gives approximate results just like equation (6), although it takes into account a larger number of parameters. Equation (7) does not take into consideration: the influence of refraction, the different distance of observer-top of the object and observer - shore horizon, tides, error in the Dip of the shore horizon, etc. One of the biggest problems in equation (7) is establishing the Dip of the shore horizon. To establish the Dip of the shore horizon (equation 8) the distance of the shore horizon is required, i.e. the distance that is basically the same as the variable required. The application of equation 7 (and 8) requires that the distance of the shore horizon be:

- empirically estimated by the observer,

- $\quad$ calculated via equation (7) (without taking into account the Dip),

- $\quad$ calculated via equation (7) with assumption that Dip is same like the Dip $_{\text {sea }}$ or

calculated via equation 5 or 6 .

All of the above mentioned methods of estimation (calculation) of the distance of the shore horizon will generate unreliable Dip and accordingly unreliable LOP by vertical angle. Figure 12 shows an example of the impact of Dip on LOP error. $d D$ - change of Distance (n.m.); $d D i p$ - change of Dip(')

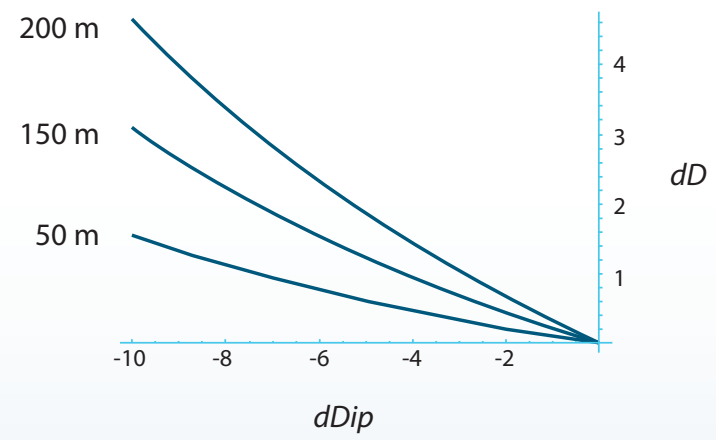

Figure 12. Impact of the Dip of shore horizon on the Distance to the observed object. Results obtained in accordance with Equation (7): $\alpha=30^{\prime} ;(\mathrm{H}-\mathrm{h})=50 \mathrm{~m}$; $100 \mathrm{~m}$ and $150 \mathrm{~m}$.
The Dip of the shore horizon has a significant impact on the error of the LOP from a vertical angle. Even a few minutes' error in Dip can cause an error of more than one nautical mile in distance.

b) Shore horizon beyond the sea horizon

When the shore horizon is beyond the sea horizon, i.e. when the shore horizon is invisible to the observer, the Dip of the sea horizon should be taken into account. Figure 13 illustrates the situation when the shore horizon is beyond the sea horizon.

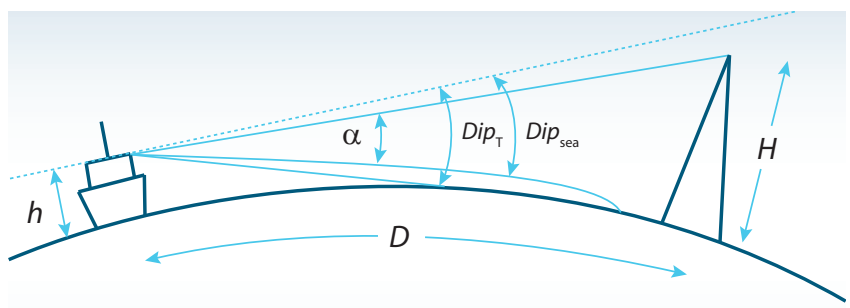

Figure 13. Distance from a vertical angle-shore horizon beyond of the sea horizon.

Distance D (Benković et al., 1986):

$D=-\left(\alpha+\right.$ dep $\left._{\text {sea }}\right)+\sqrt{\left(\alpha+\text { depsea }^{2}+3.7126(H-h)\right.}$

In this case there is no problem establishing the Dip, because the Dip of the sea horizon (equation 9) is in function only at the height of the observer's eye (for standard atmosphere ${ }^{(6)}$ ).

\subsection{Distance by vertical angle of the object if the height of the object is unknown}

Without knowing the height of the observed object, the distance from a vertical angle cannot be determined directly. Further text will present several methods of indirectly obtaining the distance from a vertical angle when the height of the object is unknown. All methods will be based on a simple case, i.e. the surface of the Earth will be considered flat, the eye of the observer at sea level and the impact of the atmospheric refraction and the Dip negligible.

a) Distance from a vertical angle - two observations at two different times

If the course towards the object is maintained, with two observations of the same object and if the distance between the observation points is known, the distance to the object can be calculated (Figure 14). 


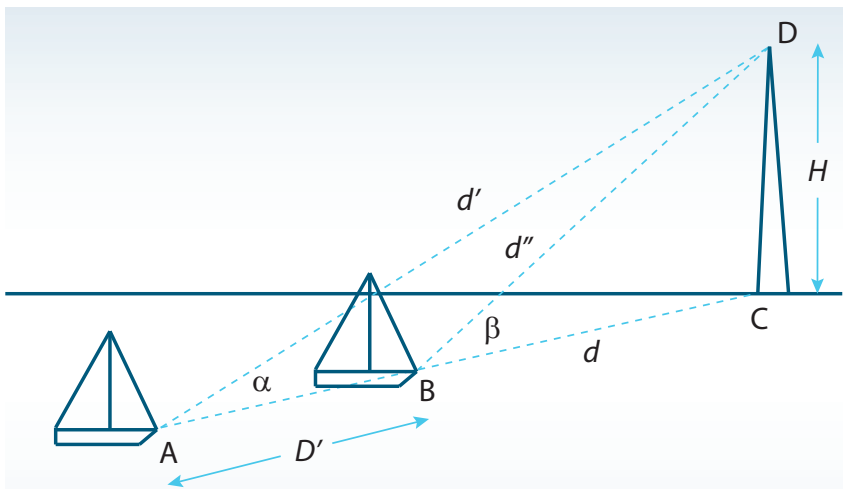

Figure 14. Distance from two vertical angles in two observations - height of object unknown.

Procedure (Figure 14): At point A measure the angle $\alpha$. Move the ship a known distance $D^{\prime}$ (point $\mathrm{B}$ ) and measure the angle $\beta$ (Ifland, 2002). From the triangle $A B D$ :

$d^{\prime \prime}=D^{\prime} \frac{\sin \alpha}{\sin (\beta-\alpha)}$

From triangle $B C D$ distance $\mathrm{d}$ is equal:

$d=D^{\prime} \frac{\sin \alpha}{\sin (\beta-\alpha)} \cdot \cos \beta$

and height of the object is:

$H=D^{\prime} \frac{\sin \alpha}{\sin (\beta-\alpha)} \cdot \sin \beta$

In case that ship is not on course towards the object, distance $d$ is:

$d=D^{\prime} \cdot \cos L \frac{\sin \alpha}{\sin (\beta-\alpha)} \cdot \cos \beta$

$L$ - relative bearing on the object.

This method is almost the same as the method calculating the distance of an object by two bearings, for which there are tables with final results ${ }^{(7)}$. The only difference is that the situation in Figure 14 is placed in the vertical rather than the horizontal plane.

b) Distance from a vertical angle - use of height of own vessel Basically, this method requires the use of a sextant with artificial horizon.

Procedure (Figure 15): At the ship's deck (lower level) measure the angle $\alpha$. Climb to the top of the mast (upper level), a known height, and measure angle $\beta$ using an artificial horizon (Ifland, 2002).

$7 \quad$ Nautical table 8 (Nautičke tablice,1999), Table 18 (Bowditch, 2002). Result for distance abeam, from these tables, corresponding to the height of the object (equation 15).

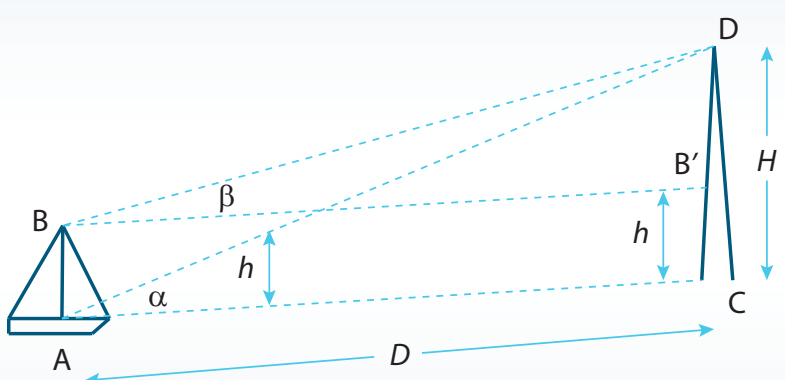

Figure 15. Distance from two vertical angles with use of height of own vessel - height of object unknown.

$\tan \beta=\frac{D H}{D}$ and $\tan \alpha=\frac{h+D H}{D}$.

Accordingly,

$H=h+D H=h+\frac{h \cdot \tan \beta}{(\tan \alpha-\tan \beta)}$

To determine distance $D$, equation (5) can be used.

A simplified solution can be reached if we use the height of our own ship to determine the angle of parallax $\pi$ (Figure 16).

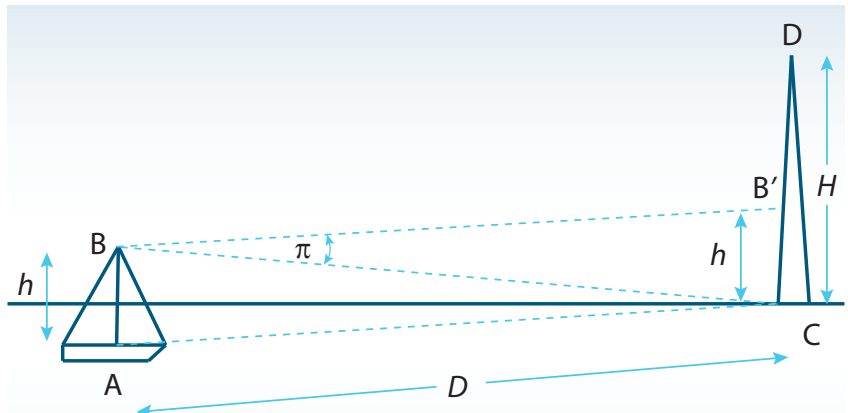

Figure 16. Distance from vertical angles with use of height of own vessel and parallax angle $\pi$.

From triangle $A B C$ (Figure 16):

$\tan \pi=\frac{h}{D}$

and finally (see equation 2):

$D=\frac{h}{\tan \pi}$

c) Distance from a vertical angle - two observations with the same vertical angle 
Two observations of the same object, each with the same vertical angle (or ship in movement with the same vertical angle on the object), allow the easy establishment of distance to the object (Figure 17).

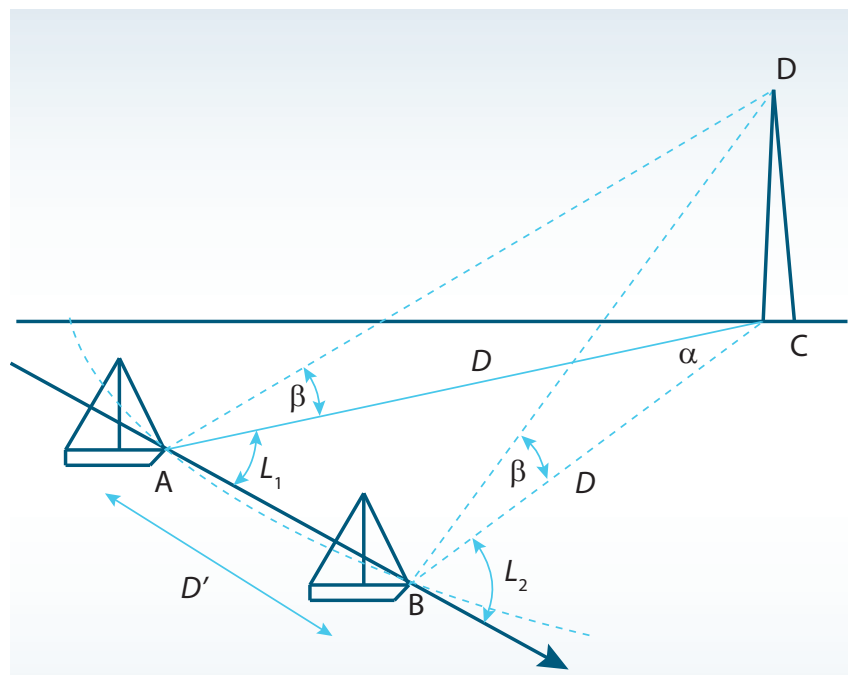

Figure 17.

Two observations with the same vertical angle.

$\alpha \quad$ - horizontal angle $\left(L_{2}-L_{1}\right)$,

$\beta$ - vertical angle,

$L \quad$ - relative bearings.

Situation in Figure 17 can be described as special case of situation in Figure 14.

Distance to the object $D$ :

$D=\frac{D^{\prime}}{2 \sin \frac{\alpha}{2}}$

or (in case of sailing under the same vertical angle and under the assumption that $D^{\prime}$ is equal to the arc of the circle having radius $D): 360: \alpha=2 D \pi: D^{\prime}$.

$D=\frac{360 \cdot D^{\prime}}{2 \cdot \pi \cdot \alpha}$

d) Distance from a vertical angle - use of two ships

Instead of making two or more observations from one ship, distance to the object can also be obtained from two or more ships (Figure 18). One of the requirements is that the ships communicate with each other.

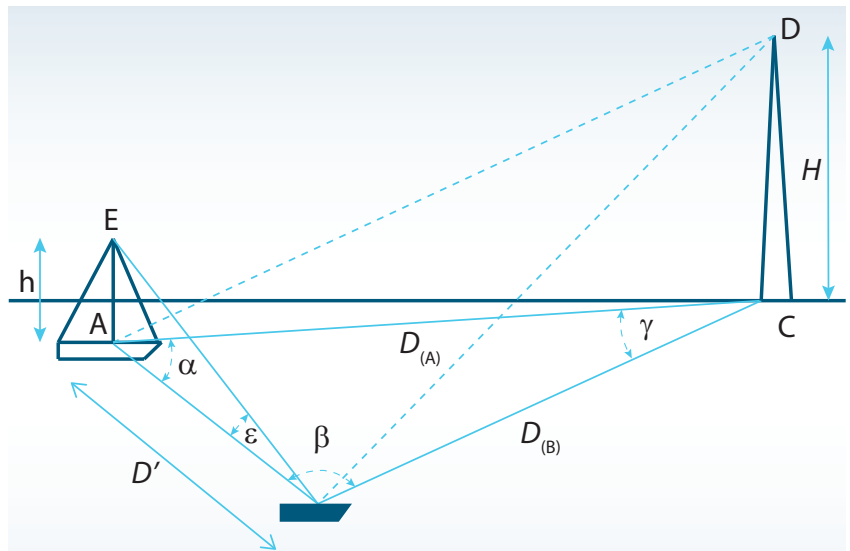

Figure 18. Distance from a vertical angle-use of two ships.

$\alpha, \beta, \gamma \quad$ - horizontal angles,

$\varepsilon \quad$ - vertical angle,

$D_{\text {(A) }} \quad$ - distance to the object from ship A,

$D_{(B)} \quad$ - distance to the object from ship B,

$D^{\prime} \quad$ - distance between ship A and ship B,

$H \quad$ - height of ship A.

Solution I (Ifland, 2002)

Ship B measures the vertical angle of ship A $(\varepsilon)$, knowing the height of ship A. Also, ship B measures the horizontal angle $\beta$ (between ship $\mathrm{A}$ and the object), while ship $\mathrm{A}$ measures the horizontal angle $\alpha$ (between ship B and the object). Using the vertical angle $(\varepsilon)$ and the height of ship A $(h)$, ship B calculates the distance $D^{\prime}$. Knowing the horizontal angles $(\alpha, \beta, \gamma)$ and the distance $D^{\prime}$, equation (3) can be used to obtain distances $D_{(\mathrm{A})}$ or $D_{(\mathrm{B})}$ (see Figure 8).

\section{Solution II}

Ship B may be considered the second position of ship A. Provided there is mutual exchange of information between the ships, the situation can be considered the same as in 3.2. a) (see figure 14), and accordingly, equation (16) can be applied.

\section{LOP ERROR}

Navigational errors are usually divided into three main types (Benković et al., 1986):

- mistakes,

- $\quad$ systematic errors, and

- $\quad$ random errors.

A mistake is a blunder of the observer, for example: incorrect reading of an instrument, data entry error, wrong calculation, etc. Systematic errors are those which follow some 
rule and which can be predicted, for example: index error of the sextant, chronometer error (CE - difference between GMT and chronometer time), error of the compass that is the same in all directions, etc.

Random errors are unpredictable and follow the laws of probability. Due to random errors, navigational measurements are usually normally distributed around a mean, or average, value (Bowditch, 2002).

If it is assumed that mistakes of the observer and systematic errors occur with the same frequency when determining the different types of LOPs, the random error will have the greatest importance in defining the accuracy of these LOPs. Figure 19 shows how random errors cause the shift of LOP for bearing and distance.

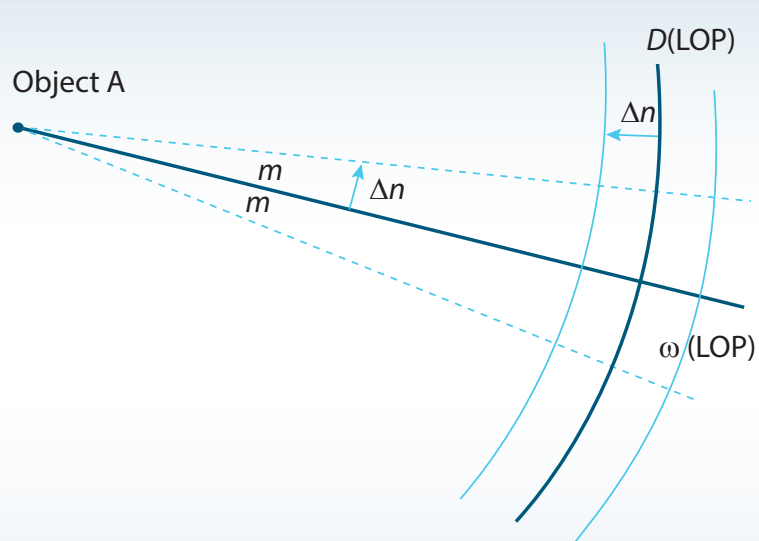

Figure 19. Shift of LOP for bearing ( $\omega)$ and distance (D).

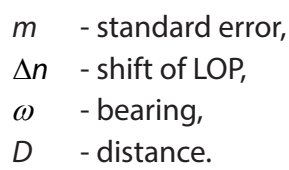

Shift of bearing ( $\Delta n)$, in function of the distance $(d)$ to the object, can be calculated by the following equation (Benković et al., 1986):

$$
\Delta n=\frac{m^{\circ} \cdot d}{57.3^{\circ}}=\frac{m^{\prime} \cdot d}{3438}
$$

while the Shift of distance $(\Delta n)$ is equal to the standard error $(m)$.

LOP for a horizontal angle (or vertical) is a circle, i.e. same as for distance. Shift of LOP for a horizontal angle (Figure 20) can be calculated by the following equation (Benković et al., 1986):

$\Delta n=\frac{m^{\circ} \cdot d A \cdot d B}{A B \cdot 57.3^{\circ}}=\frac{m^{\prime} \cdot d A \cdot d B}{A B \cdot 3438}$ $d A$ - distance from observer to the object $A$,

$d B$ - distance from observer to the object $B$,

$A B$ - distance between object $A$ and $B$,

$m$ - standard error.

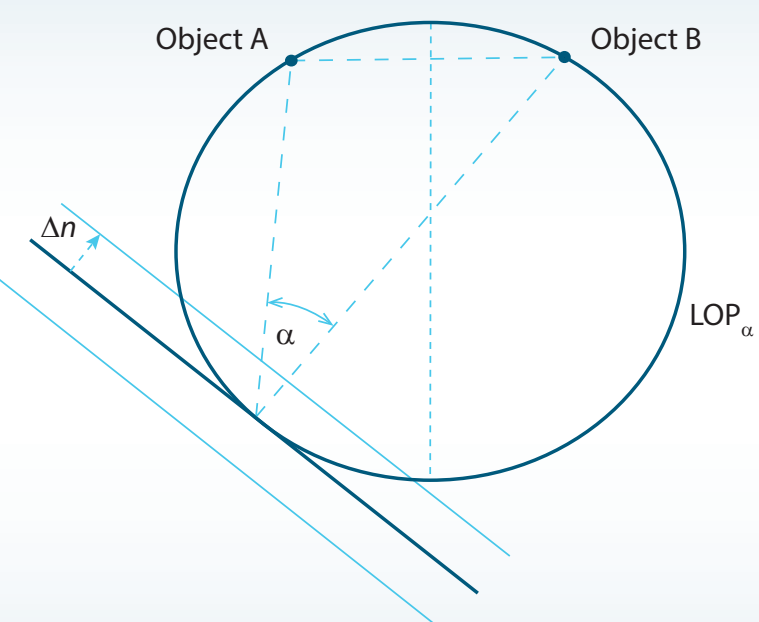

Figure 20. Shift of LOP for a horizontal angle.

Example: Let's take a bearing accuracy of $+/-0.5^{\circ}$ and distance accuracy of $+/-0.5 \%$ of the distance (MSC.192) and let these limits represent standard errors. Also, let the standard error of the sextant be $+/-1$ ', for measuring horizontal angles. Figure 21 shows the result.

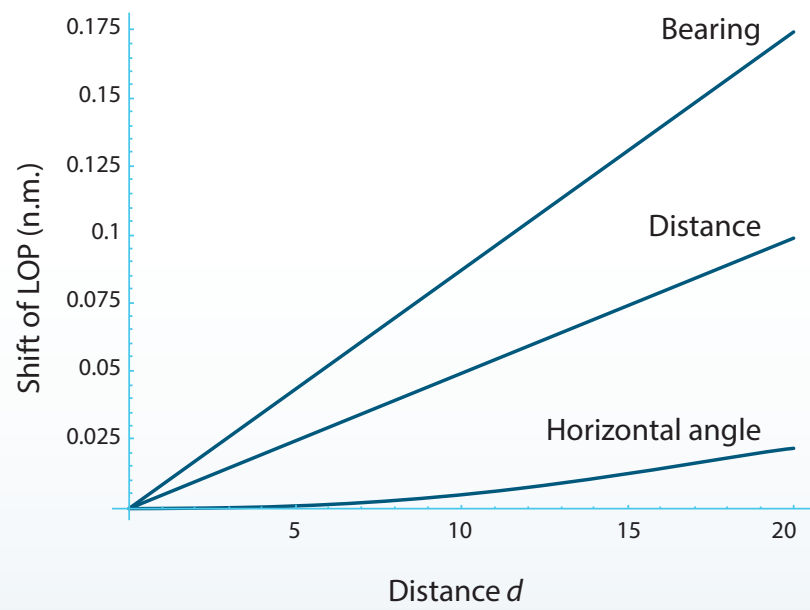

Figure 21. Comparison of shift of of LOP for bearing, distance and horizontal angle (for horizontal angle: distance $A B=5$ n.m., $d A=d B$ ) 
All of the above confirms that the line of position from a horizontal angle (measured by sextant) is more accurate than the line of position from distance or azimuth.

Vertical angles theoretically have the same advantages as horizontal angles. However, in practice the situation is quite different. As already mentioned in section one, the main reasons for the lesser accuracy of the LOP from a vertical angle in relation to the LOP from a horizontal angle are: the influence of the Dip of the sea (or shore) horizon, the height of the observer's eye and the height of the observed object. The influence of the Dip of the shore horizon on LOP error has already been explained (section 3.1., Figure 12). Even a one minute error in Dip can cause an error in distance greater than one nautical mile. The Dip of the shore horizon has the function of distance to the shore, and since the distance is unknown to the observer, an error in Dip is inevitable.

The Dip of the sea horizon is much easier to calculate (equation 9). However, the occurrence of errors can also be expected and the main reasons are: error in the height of the observer's eye and empirically taken influence of refraction (for example: in the Croatian nautical table the Dip of the sea horizon is $8 \%$ lower than true Dip) (Nautičke tablice, 1999).

The height of the observer's eye above sea level can be precisely determined, but the height of the observed object above sea level is questionable. The main reason is that the actual sea level is different than the one in the navigation map (correction for height of tide is required). Also, some facts to keep in mind (Coolen, 1987): the charted height of an object can be given above Mean High Water Spring, Mean High Water Neap or Mean Sea Level; for lighthouses, charted height is measured from the chosen level to the centre of the focal plane of the light; in publication "List of lights", the "Height" of a light refers to the height of the structure measured from the top of the structure to the ground, although the action of natural or artificial forces may cause the actual height to differ from that on the map, etc.

Even the sextant has error, and an index error is usually synonymous with several errors that can be determined and taken into consideration. In all situations when distances are calculated from a vertical angle (and horizontal angle), the observed angle should be taken into account instead of the sextant angle. The sextant angle is the actual angle, i.e. the angle read from the sextant. The observed angle is the sextant angle corrected for index error.

Due to all these facts, generally, the distance from a vertical angle will not have the same accuracy as distance from a horizontal angle. However, this does not diminish the importance of the vertical angle and its usefulness in terrestrial navigation. A good navigator will be able to use it just as well as the horizontal angle, or as radar bearing and distance.

\section{CONCLUSIONS}

Although the establishment of LOPs from horizontal and vertical angles requires certain additional skills, the methods of establishing LOPs are, in the end, not that complicated. These methods can also be considered a part of the basic know-how and skills of navigators. The availability of modern navigational aids and present-day simplicity of determining one's position at sea do not mean that traditional knowledge should be forgotten and not used in practice. Among other things, the sextant is still a mandatory instrument on board and should be used daily or at least occasionally to maintain the skills of handling it. The line of position obtained from a horizontal angle using sextant can be very accurate, much more so than azimuth and distance. On the other hand, the line of position obtained from a vertical angle may be less reliable, not because of the sextant, but due to other errors mainly resulting from the curvature of the Earth and the existence of the Earth's atmosphere. At small distances from the coast and if the height of the eye of the observer is low, these errors are negligible. Finally, we can say that the importance of vertical and horizontal angles in terrestrial navigation is much greater than appears at first glance, and that those who don't have a sextant on board (or don't know how to use it) do not know how much they are losing.

\section{REFERENCES}

Benković, F., Piškorec, M., Lako, Lj., Čepelak, K. and Stajić, D., (1986), Terestrička i elektronska navigacija, Split: Hidrografski Institut Ratne mornarice.

Bowditch, N., (2002), The American Practical Navigator, Bethesda: National Imaginary and Mapping Agency.

Coolen, E., (1987), Nicholls's Concise Guide to Navigation - Volume 1 (10th Edition), Glasgow: Brown's, Son \& Ferguson Ltd

Coolen, E., (1995), Nicholls's Concise Guide to the Navigation examinations - Volume 2 (12th Edition), Glasgow: Brown's Son \& Ferguson Ltd.

Gyro compass repeater, available at: http://www.flickr.com/photos/jerry_ lake/8012287253, [accessed 14 December 2012.].

Ifland, P., (2002), Finding Distance-Not Knowing Height (Forum), The Journal of Navigation, 55(3), pp. 495-500.,

http://dx.doi.org/10.1017/S0373463302212023

Kos, S., Zorović, D., and Vranić, D., (2010), Terestrička i elektronička navigacija, Rijeka: Pomorski fakultet u Rijeci.

Nautičke tablice, (1999), Split: Hrvatski hidrografski institute.

Nautical Compasses, avaialble at: http://www.compassmuseum.com/nautical/ nautical_2.html (bearing sight), [accessed 15 December 2012].

Norie's Nautical Tables, (1999), London: Imray Laurie Norie and Wilson LTD.

Resolution MSC.192(79)-Annex 34, Adoption of the revised performance standards for radar equipment, available at: http://www.imo.org/blast/blastDataHelper. asp?data_id=15568\&filename $=192 \% 2879 \% 29 . p d f$

Simović, A., (2001), Terestrička navigacija, Zagreb: Školska knjiga. 